\title{
Modifications des composants volatils du yoghourt bulgare
}

\author{
par \\ Maria S. KONDRATENKO et Bojana Chr. GUIOCHEVA \\ Laboratoire central d'industrie laitière \\ 134, bd 9 Septemvri, Sofia 1618, Bulgarie
}

Le yoghourt bulgare a un goût et un arôme spécifiques qui le différencient des autres produits yoghourtiers.

L'application de la chromatographie en phase gazeuse pour l'analyse de l'arôme des produits yoghourtiers a permis d'étudier le changement de la teneur en substances volatiles au cours de la conservation du yoghourt [1] et du kéfir [2].

Nous manquons de résultats concernant l'accumulation et la modification des substances volatiles aromatiques lors de l'obtention et de la conservation du yoghourt bulgare.

Le but de la présente étude est d'établir lesquelles des substances volatiles aromatiques sont transmises par le lait pasteurisé et lesquelles apparaissent et disparaissent lors de la culture et de la conservation du yoghourt bulgare.

\section{MATERIEL ET METHODES}

Pour la préparation des échantillons on utilise une culture lactique liquide, la combinaison 5-12, inoculée dans du lait de vache entier passé à l'autoclave.

On homogénéise et pasteurise le lait de vache entier à la température de $92-95^{\circ} \mathrm{C}$ en le maintenant ensuite durant 30 minutes à cette même température. Ensuite, on le refroidit à $45^{\circ} \mathrm{C}$. On met dans le lait du ferment lactique à 2 p. 100 et le lait ensemencé est mis au thermostat à $45^{\circ} \mathrm{C}$ pour amener l'acidité à $25^{\circ} \mathrm{T}$. Ensuite le lait est versé dans des bocaux stériles et mis au thermostat à $32^{\circ} \mathrm{C}$ pour coaguler. Lorsque l'acidité atteint $84^{\circ} \mathrm{T}$, on le met au réfrigérateur. La conservation se fait à $+4^{\circ} \mathrm{C}$. 
Nous avons prélevé également des échantillons de lait pasteurisé à la $30^{\circ}, 60^{\circ}, 90^{\circ}, 120^{\circ}, 150^{\circ}, 180^{\circ}$ et $210^{\circ}$ minute après l'introduction du ferment lactique et lors de la conservation au bout du 1, 2, 10, 15 et 30 jours. Avant chaque analyse nous avons procédé à une dégustation anonyme.

La modification des substances volatiles durant la conservation et l'obtention du yoghourt bulgare a été analysée à l'aide de la chromatographie en phase gazeuse. Les prélèvements de substances volatiles aromatiques ont été effectués suivant la méthode «Head space ». Dans une ampoule médicale de $25 \mathrm{ml}$ on avait mis au préalable $2 \mathrm{~g}$ de sulfate de sodium déshydraté en y ajoutant ensuite $2 \mathrm{~g}$ de chaque échantillon de yoghourt homogénéisé. Les ampoules ont été hermétiquement fermées et conservées à $-13^{\circ} \mathrm{C}$. Avant l'analyse, les prélèvements avaient été décongelés et chauffés au bain-marie à $60^{\circ} \mathrm{C}$ durant 10 minutes. De l'espace gazeux enrichi en substances volatiles on a prélevé $1 \mathrm{ml}$ qui fut réinjecté dans la colonne du chromatographe en phase gazeuse. On a utilisé le chromatographe "Fractovap », modèle " D ", société « Karlo Erba ", avec détecteur à ionisation de flamme. La colonne a été chargée à 10 p. 100 de PEG-400 sur chromosorb W silanisé 60-80 mesh. L'identification des pics a été réalisée suivant deux méthodes :

- chromatographie en phase gazeuse en utilisant les temps de retenue relatifs à des phases de polarité différentes ;

- méthodes spectrales, spectrographies IR et NMR.

Les méthodes d'identification, voir [3].

\section{RESULTATS ET DISCUSSION}

L'analyse du lait pasteurisé par la chromatographie en phase gazeuse (fig. 1) a relevé la présence de sept substances: pics $n^{\text {os }} 1,2$, 3 , non identifiés; $n^{\circ} 4$, traces d'acétaldéhyde ; $n^{\circ} 5$, acétone ; $n^{\circ} 7$, butanone-2, et $n^{\circ} 9$, éthanol. L'éthylacétate et le diacétyle sont absents. Les substances non identifiées contenues dans le lait pasteurisé restent invariables durant l'incubation et sont sans importance pour le présent travail.

Sur la figure 2 on présente le chromatogramme des substances volatiles aromatiques contenues dans le yoghourt bulgare au moment de la coagulation à $84^{\circ} \mathrm{T}$ d'acidité. Le yoghourt bulgare contient les substances aromatiques suivantes: pics $\mathrm{n}^{\circ \mathrm{s}} 1,2,3$, non identifiés; $n^{\circ} 4$, acétaldéhyde ; ${ }^{\circ} 5$, acétone ; $n^{\circ} 6$, éthylacétate ; n 7 , butanone-2; $n^{\circ} 8$, diacétyle ; $n^{\circ} 9$, éthanol.

L'analyse à l'aide de la chromatographie en phase gazeuse démontre, une heure après l'inoculation, qu'il est intervenu un changement essentiel de la hauteur du pic de l'acétaldéhyde, ce qui 


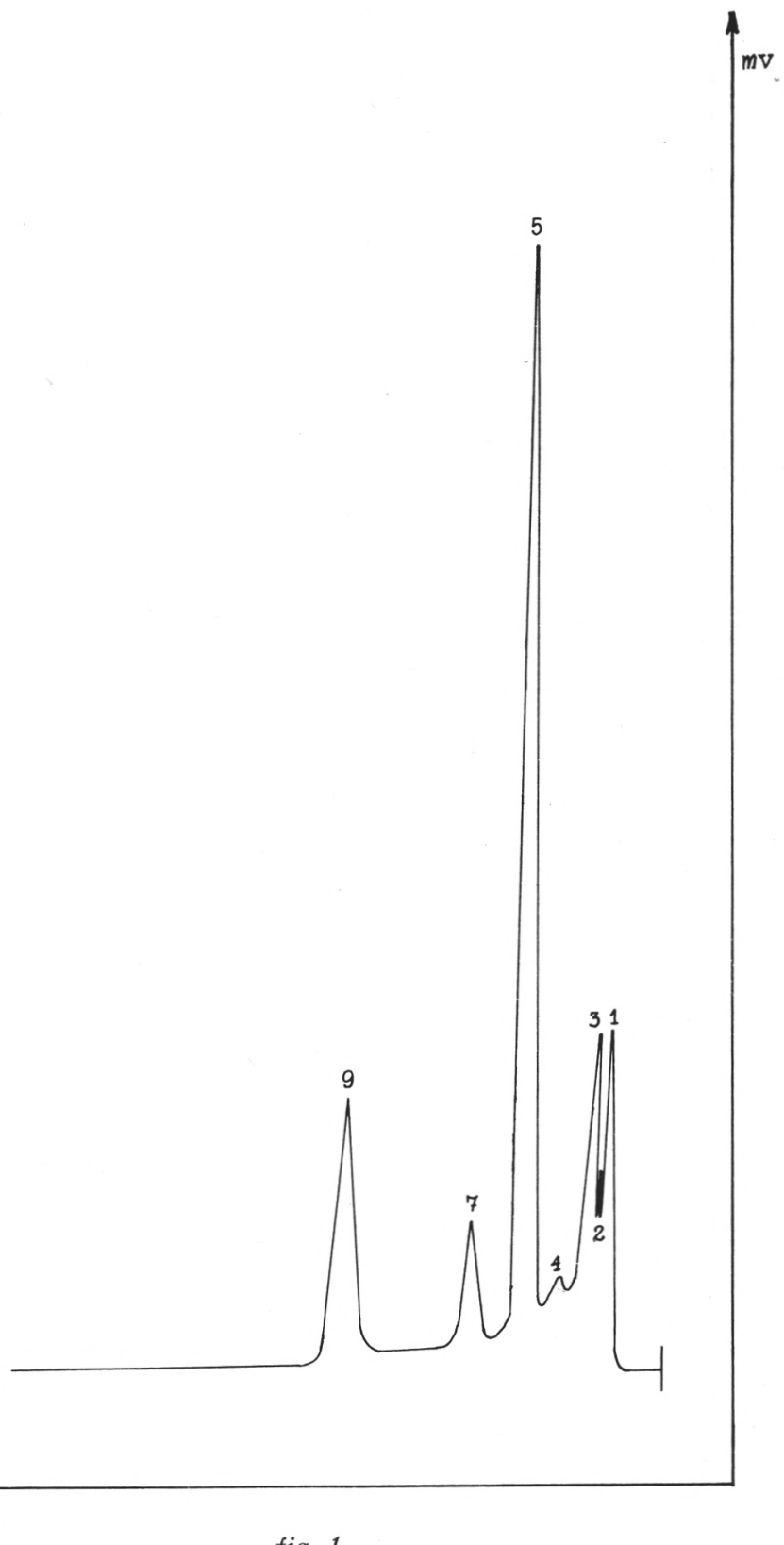

fig. 1

Chromatogramme des composants volatils aromatiques contenus dans le lait pasteurisé. Les pics sont : 1, 2, 3 : non identifiés ; 4 : acétaldéhyde ; 5 : acétone ; 7 : butanone-2 ; 9 : éthanol. 


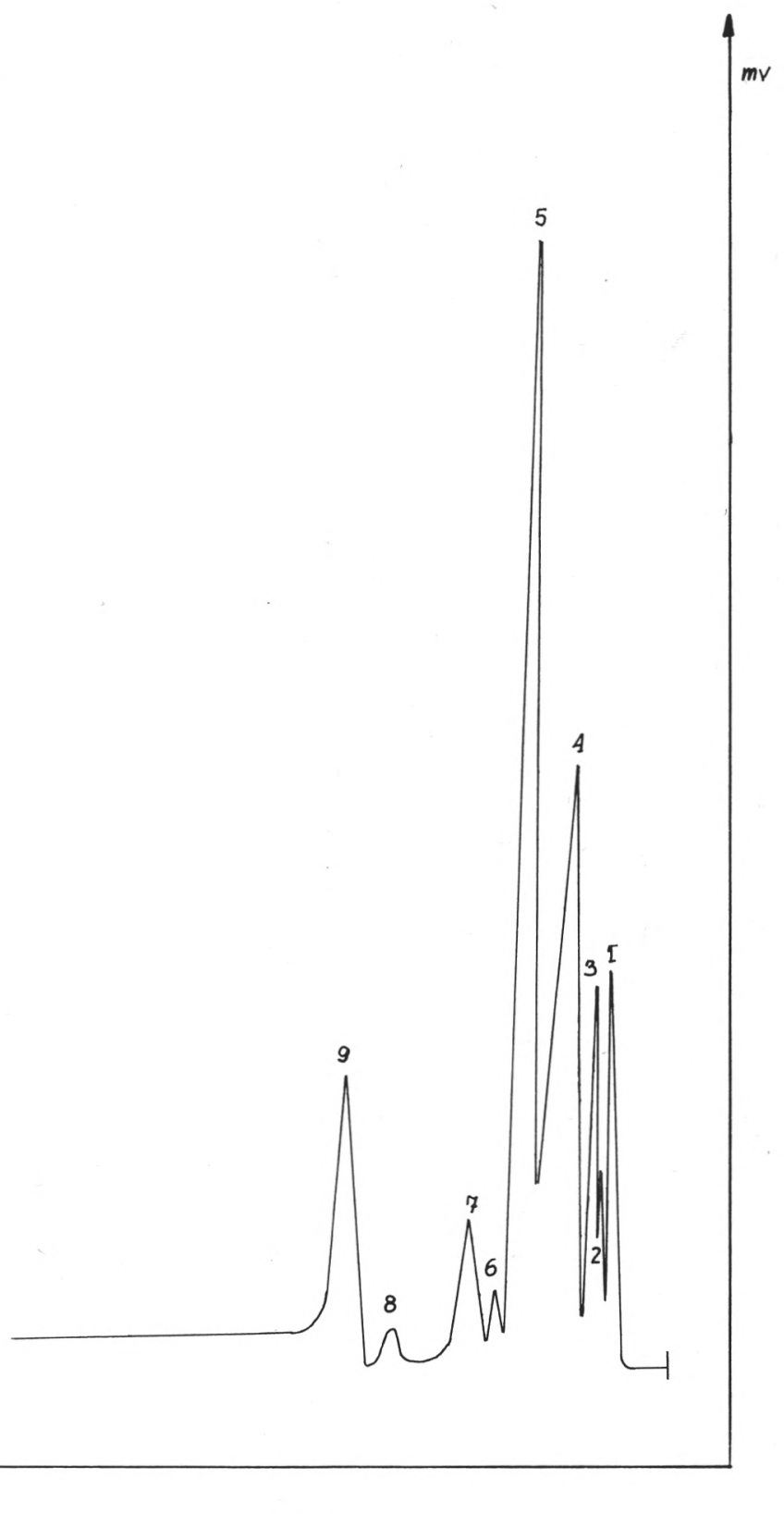

fig. 2

Chromatogramme des composants volatils aromatiques contenus dans le yoghourt bulgare à $84^{\circ} \mathrm{T}$ d'acidité au moment de la coagulation. Les pics sont $1,2,3$ : non identifiés ; 4 : acétaldéhyde ; 5 : acétone ; 6 : éthylacétate ; 7 : butanone-2 ; 8 : diacétyle ; 9: éthanol. 
témoigne de l'accroissement de la qualité d'acétaldéhyde. Deux nouveaux pics apparaissent pour relever l'éthylacétate et le diacétyle.

Pour visualiser le changement quantitatif des différentes substances volatiles lors de la culture et de la conservation du yoghourt bulgare, des colonnes graphiques sont présentées à la figure 3 . On voit que la teneur du lait en acétaldéhyde est minime une heure après l'introduction du ferment lactique. La quantité d'acétaldéhyde commence à augmenter après la première heure et atteint sa valeur maximale lors de la coagulation. La quantité d'acétaldéhyde reste
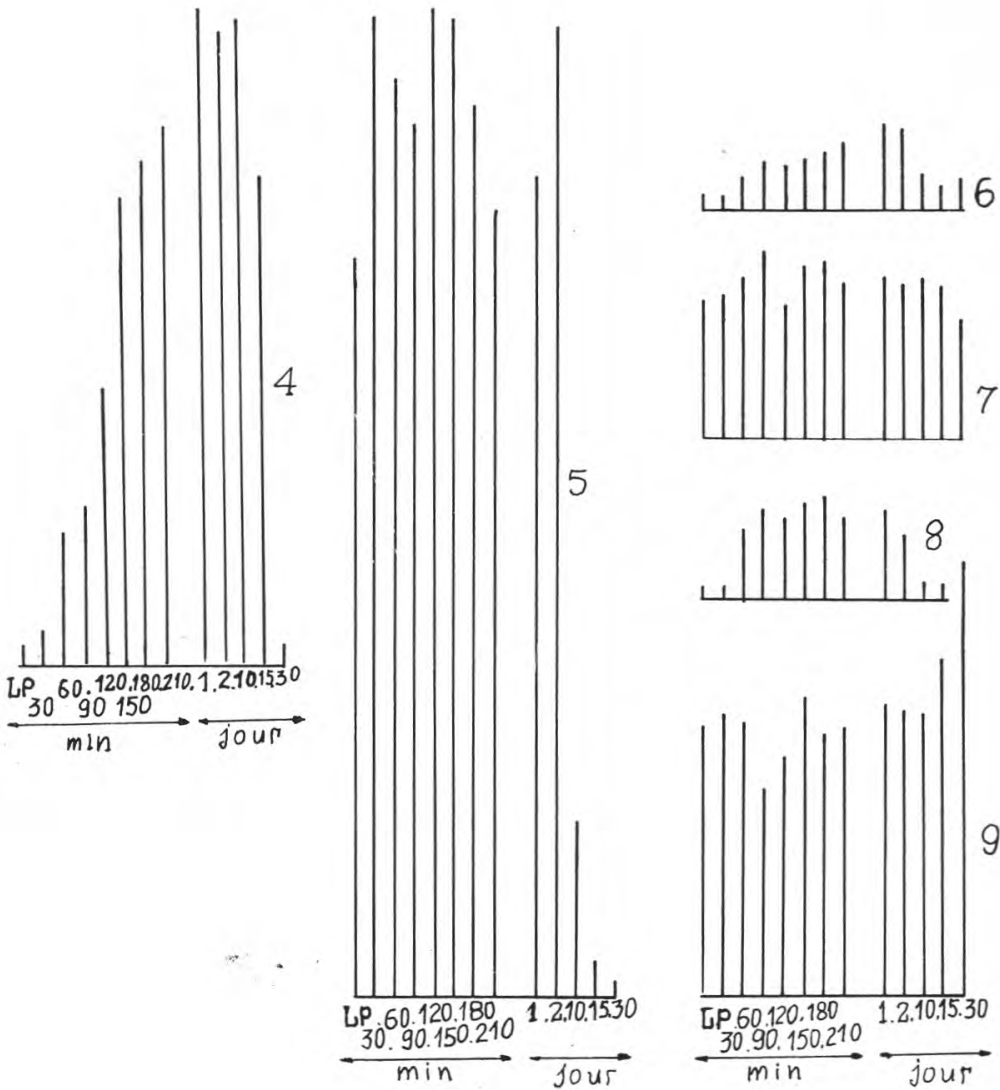

fig. 3

Graphique du changement de certains composants volatils aromatiques durant l'inoculation et la conservation du yoghourt bulgare. Les graphiques sont 4 : acétaldéhyde ; 5 : acétone ; 6 : éthylacétate ; 7 : butanone-2 ; 8 : diacétyle ; 9 : éthanol. 
invariable jusqu'au $10^{\circ}$ jour lors de sa conservation. Ensuite, elle commence à baisser. La teneur en éthanol, en acétone et en butanone-2 reste invariable au cours de la culture. Lors de la conservation du yoghourt, la quantité d'acétone diminue le $2^{\mathrm{e}}$ jour passé, la quantité de butanone-2 ne changeant pas, tandis que la quantité d'éthanol s'accroît après le $10^{\circ}$ jour. Le diacétyle et l'éthylacétate apparaissent une heure après l'introduction du ferment lactique et augmentent progressivement jusqu'à la coagulation. Après 2 jours de conservation, ils diminuent progressivement et le $30^{\circ}$ jour, on n'en trouve plus que des traces.

L'appréciation organoleptique des échantillons analysés a montré que jusqu'au $15^{\circ}$ jour de conservation, ceux-ci ont un goût de lait caillé et un arôme bien marqué. Au $30^{\mathrm{e}}$ jour de conservation, le goût de lait caillé est conservé, mais une certaine atténuation de l'arôme est constatée.

\section{CONCLUSIONS}

L'étude de la cinétique de formation des substances volatiles aromatiques durant l'obtention et la conservation du yoghourt bulgare permet d'arriver aux conclusions suivantes:

1. Les substances supposées être responsables de l'arôme du yoghourt bulgare sont: acétaldéhyde, acétone, éthylacétate, butanone-2, diacétyle et éthanol.

2. L'acétaldéhyde, en quantité maximale au cours de la coagulation, reste invariable jusqu'au $10^{\mathrm{e}}$ jour de conservation du lait à une température de $+4^{\circ} \mathrm{C}$. Ensuite, sa quantité diminue.

3. L'acétone diminue après le $2^{e}$ jour de conservation du yoghourt bulgare.

4. La quantité du butanone-2 ne change pas jusqu'au $30^{\circ}$ jour.

5. La quantité d'éthanol augmente après le $10^{\circ}$ jour.

6. Le diacétyle et l'éthylacétate augmentent jusqu'au moment de la coagulation. Après le $2^{\text {e }}$ jour de conservation leur teneur commence à diminuer.

\section{$R$ és u m é}

On a étudié la modification des composants volatils aromatiques responsables, à un certain degré, de l'arôme du yoghourt bulgare au cours de sa culture et de sa conservation. On a établi que, parmi les composants intervenant dans la formation de l'arôme du yoghourt bulgare, c'est l'acétaldéhyde qui est en quantité prédominante au moment de la coagulation et dont la teneur reste invariable jusqu'au $10^{\mathrm{e}}$ jour de conservation. Le diacétyle et l'éthylacétate augmentent jusqu'au moment de la coagulation. Après le 
$2^{\text {e }}$ jour de conservation, il commence à diminuer. L'acétone diminue après le $2^{\mathrm{e}}$ jour de conservation. La quantité de butanone- 2 ne change pas jusqu'au $30^{\circ}$ jour, tandis que celle de l'éthanol augmente après le $10^{\circ}$ jour.

\section{S u $\mathrm{m}$ m a ry}

\section{CHANGES IN VOLATILE COMPONENTS OF BULGARIAN YOGHURT}

Changes in volatile components, partially responsible for the flavour of Bulgarian yoghurt, are followed during its cultivation and storage. It was found that of the substances taking part in the formation of Bulgarian yoghurt flavour, acetaldehyde is presented in a maximum quantity at the time of coagulation and is preserved unchanged till the tenth day of storage. Diacetyl and ethylacetate raise till the time of coagulation and they begin to grow lower after the second day of storage. Acetone is reduced after the second day of storage. The quantity of butanone-2 is not changed till the thirtieth day and ethanol grows higher after the tenth day.

Reçu pour publication en avril 1978.

\section{Bibliographie}

[1] Gorner (F.), Palo (V.) und Bartan (Mathilde). - Milchwiflenschaft, 23/2, 777-785, 1972.

[2] Gorner (F.) Palo (V.) und Sedin (M.). - Die Hahrung, 16, 7, 777-785, 1972.

[3] Z. Gioucheva (B.) et Roussev (P.). - Additif à la méthode spectrale et de chromatographie en phase gazeuse pour l'étude du parfum dans le yaourt bulgare. Troisième conférence nationale sur la chromatographie, avec la participation de pays étrangers, Varna, 1977. 